\title{
Study on the Concept and Practice of Music Education of a Taiwanese Singer Ren Rong
}

\author{
Qin Yin
}

Xiamen University, Xiamen, Fujian, 361005

\author{
Keywords: Renrong, Music Education, Concept and Practice
}

\begin{abstract}
Ren Rong is a famous soprano singer in Taiwan. She graduated from the Music Department of National Taiwan Normal University and went to Italy in the fall of 1965 . She graduated from the National Rome Conservatory and won the best vocal graduation scholarship in Rome. She has a distinguished position and great influence in the vocal music art education in Taiwan. She has made outstanding achievements not only in professional and musical arts, but also has made her long-term unremitting efforts in spreading the lofty culture. Until now, she is still trying to cultivate students, practice their professional music education ideas. For more than two decades, she has curated opera and performing arts programs in Italy and Taiwan and held "The Chinese Vocal Competition in the World" for eight years, attracting the attention and appreciation of international musicians. However, for such an outstanding artist in the field of vocal music teaching, her concern and research in mainland China are few. This paper aims to make an in-depth analysis and comment on Ren Rong's concept of music education so as to deepen more readers' understanding.
\end{abstract}

\section{Introduction}

Singing is a comprehensive art of expression. It is not merely a simple vocalization. It requires singers to interpret responsible human emotions such as love, hatred, sadness and joy in a singing manner. Singing and speaking in everyday life are quite different in how they sound, how they feel, how often they talk, how often they breathe, which is why some people, though having a good voice, still have no reason to become singers. As someone once pointed out sharply, "singing refers to using good voice, scientific singing skills, good musical and cultural qualities and truly rich thoughts and feelings to convey the songs to the audience." For the vocal performance, from the vocal, breathing, resonance, pronunciations and the singing style of the song, the difference between the artistic methods of treatment can be roughly divided into three kinds of singing methods: beauty, nationality and pop. From the 1980s to the present, this method of division has been gradually recognized by the music industry. Ms. Ren has mainly studied Italian vocal music. In her decades of vocal education, Renrong has always emphasized that "pronunciation and biblical writing are the soul of singing." "People who can not speak words can not sing."

The most important issue for the study of Italian vocal singing is the pronunciation technique training of the vocal song. In the music industry, senior leaders pointed out sharply that the three most important problems plaguing beginners are the scientific vocal training and the skill training required for opera performances, in addition to pronouncing words and puncturing them. In traditional vocal teaching, some teachers unilaterally emphasize a wide range of technical issues (such as pitch, pitch and range), or superficial and even illusory "vocal feelings", ignoring the fact that singing itself is primarily a matter of vocal skill Technical problems. This has led some newly-started students have no way to master the scientific and effective occurrence of skills, spent years and even destroyed his singing career. Ms. Ren Rong not only pays great attention to sensory experience in the teaching process, but also pays more attention to finding a suitable training method for each student's voice characteristics. She believes that there is actually no set of uniform training objectives or training methods for the Vocal teaching method because all training ultimately depends on the sound foundation students have. She pointed out that the basic principle of Bel Canto teaching should be: When young singers start practicing their songs and preparing their 
tracks, they should plan their voices within a certain range, decide which kind of voices they should first learn, and what tracks they should learn, So that the singer in the process of singing, with their own tracks without going so far as to damage the natural voice of reason, or cause the lessons learned can not contribute to the development of sound and so on.

\section{Ren Rong's artistic expression of emotion in the show}

Everyone who learns beautiful singing knows that the unity of singing and feeling, that is, "having the best of both worlds," is the perfect ideal of singing. Is the so-called "poetry for the music of the word, music is the voice of poetry; sound to love as the source, the situation at random", if the singer can not create a singing mood, showing emotion, you can not "pass through the characters straight to the human singing." Beautiful voice state should be "in love with the sound, with the sound", but not without a good voice. The famous German soprano Schuetrethorn, though without good singing voice and sounding method, should have a smooth and graceful sound but should be famous for his fluent and energetic features. The composer Wagner once commented: "She does not have a voice at all, but she breathes, sings with a wonderful sense of music and a pure soul of a woman, so that she does not think about singing or thinking about her voice." Visible, with "heart" singing is how important.

Ms. Ren Rong summarizes the process of the vocal song training method, paying particular attention to the mental state of emotional expression and believes that it is essential to help vocal organs return to their essence with such a purely irrational factor. She repeatedly warned young people to sing," be an artist artista, do not only do singer cantante". In the emotional way of expression, Ms. Ren Rong think "want to analyze according to the material, because of the material sings, because of material affair". The singers not only need to sing songs, but also have a deep understanding of the unique emotions contained in different musical compositions before the concert, and on the basis of this, adjust the appearance and emotion expression during the concert so that they can be perfectly displayed in the singing process The true emotion of a musical piece is accurately communicated to the audience through the method of vocal singing. Therefore, in order to better reflect the emotional tone of the song, we must carefully analyze the national characteristics of the time background of the work, meanwhile understand the connotation of the work, earnestly understand the thoughts and feelings of songwriters, deepen the role of the song, Delicate thoughts and feelings with the song vividly show to the audience, and the audience to achieve emotional resonance.

Of course, this is not to say that the technique of sound is completely unimportant. In fact, in the emotional expression of vocal works, speed changes, sound intensity and timbre are all services for the artistic performance of vocal works. For Bel Canto, the mastery of breathing skills is a particularly important singing technique. Whether lasting, smooth and moderate breathing can affect the expression of emotional thoughts also exists. The use of strong and weak breathing, singers can freely express the emotion of musical works. Ancient Chinese music books also have a lot of breath on the discussion, such as the Tang Dynasty Festival "Folk Songs" stressed: "good singer must first tone". There is also a saying in the vocal method that "who knows how to breathe and articulate, who knows how to sing" shows the importance of breathing. As the basis of the Bel Canto, the singer is required to have full support for breath and flexibility for breathing control. Well, how can we be breathing? Rachel often teaches students that the right inspiratory method should do the following: (1) store enough gas to control the length of the sound. (2) maintain a balanced sound, which allows the singer to naturally and effortlessly sing long enough Song and stable song.

Beginners vocal singing people most likely to make mistakes, is the excessive pursuit of emotional disclosure. As some scholars have pointed out, Bel Canto emphasizes more on the inner appeal of the voice, does not require too many ways of performing, changes in the way of singing, more on the other hand, through the inherent ways of performer's voice technology and so on. Even the United States singing is extremely emotional, its performance is more modest. For over a decade of her teaching career, Ms. Ren Rong has summed up two common mistakes in the 
emotional expression of the Bel Canto: table passion and misconduct. She said in a humorous and plain language: "For the lyrics, the language is poorly understood and not well understood, the expression of emotions is prone to error ... Sometimes it can be seen that the singer only knows that the lyrics are sad and do not go deep into meaning On the sad, with very sad expression of mourning, resulting in 'table affectionate' error. Many humorous, joking song, singing lyrics' I can not love you ',' I will not love you ',' Please do not love me ',' do not be so cruel 'and so on, but the real original intention is to tease, or even show love' fall in love 'or heart' deep affection ', the song if only look at the sentence The surface, it is easy to have the wrong things.

\section{Ren Rong's music and cultural transmission ideas}

Ms Rung has not only made an important contribution not only to music teaching and music theory, but she has also made an unparalleled contribution to music distribution in recent years. As a true musician, she believes that the most important thing is to promote the popularization, specialization and systematization of music education.

When Ms Ren Rong first returned to Taiwan, vocal music in Taiwan was already very much improved. Apart from traditional folk music, trendy music such as Taiwanese opera, pop music and rap music was also very fashionable. In the aspect of vocal singing, some teachers who have received education from foreign institutions of higher learning have been teaching. The teacher of National Taiwan Normal where Ren Rong is located mainly offers introductory lectures and performance classes of Italian songs, but most of the teachers do not have much chance to sing. Ms. Ren realized that to get more Taiwanese people to understand the Bel Canto, apart from requiring students to undergo rather stringent professional training in music and comprehensive cultural literacy, she also had to offer her courses in the teaching of Bel Canto to the general public. Ren Rong has been committed to promoting orthodox vocal music. In order to make it acceptable to the public, she set up popular singing classes, teaching orthodox phonetics, practice songs and art songs. At the beginning of the class only enrolled more than 100 students, and later many originally students who also learn to join the vocal. Although these classes are non-professional, they are taught according to professional vocals. Ms. Ren also set up "Ren Rong Performing Arts Square," and through a variety of activities so that more Taiwanese people understand music, love music. On the weekends, the school organizes concerts at the National Palace Museum in Taipei. It organizes a "good time" on Wednesday afternoon at the Taipei City Propaganda Office, and a music salon on Sunday. The students are mainly responsible for the performance. This is a very good help to the improvement of the level of music appreciation enjoyed by the Taiwanese people.

Ms. Ren has been devoted to studying the combination path of the vocal song and the Chinese song, so that the beautiful Vocal song can become an important boost for singing Chinese songs. As we all know, although China does not have such refined and technical music theory as the West, the theory of sounding essence and essence in the music theory and singing theory of our country's history and folklore is the Chinese music The essence Chinese features lies in its articulation and singing, the Chinese way of articulation is not in the West, such as Beijing Opera, Kun Opera and other Chinese opera singing has a very distinct Chinese characteristics. Ms. Ren Rong combined her own experience in listening to theatrical songs and studying and singing with her relatives and friends at an early age. She believes that in order to make the Chinese vocals reach the perfect artistic realm, "beautiful" needs to be pursued besides the "correct", and the latter is precisely the acoustical method that can be involved where. Take the pronunciation of "'" as an example. Singing out melodies as "di" can be singled out as "accidental" by Xu Zhining's Xu Zhimo; phrases still to be read in parade are still pronounced as "de", such as Li Pillow "traveler's heart." In choosing what type of pronunciations, mainly to see "long" and "weak" pronunciations more vivid and sweet. In addition, breathing techniques, Ms. Ren Rong also mentioned the method of breathing in the beauty singing method for singing Chinese art songs important reference significance. In folk songs, the breathing method is based on natural chest breathing. This breathing method to ribs and sternum activity-based, inspiratory, diaphragmatic contraction, diaphragmatic bulge down, the upper abdominal organs such as liver, spleen, etc., followed by exhalation, on the contrary, the anterior 
abdominal wall inward reset. In vocal singing, this method of breathing through the shoulder to breathe, breath is not deep absorption, less capacity, affecting the expansion of the sound field and the unity of the sound zone. If you learn from the method of Breathing Breathing in the Voice of Italy, you can make the sound soft, piercing sound can be extended in a wider range to maintain the beautiful unity of the melody lines.

\section{Conclusions}

Bel canto, the Italian translation of Bel Canto, translates directly into "perfect singing," which includes the performative performance of the singer's voice, emotions, singing content, and singing skills. Will be excellent, beautiful music presented in front of people, leaving people to aftertaste, commentary, which is both the original intention of the United Voice Singing, but also the pursuit of Ms. Ren Rong's life. Vocal art is the need of education heritage, through vocal education step by step, gradually promote the need for excellent mentors, quality education. The author hopes that the exploration of Ms. Ren Rong's vocal education philosophy and practice of vocal music promotion can provide a helpful boost for the variety and diversity of vocal arts in China.

\section{References}

[1] Zhang Wenli: "On the breathing in singing", contained "Journal of Shaanxi Normal University (Philosophy and Social Science Edition)" 2007 the 36th volume, the first 161 pages.

[2] Wu Qihui: "Three Elements of the Voice of Italy," contained in "Journal of the Central Conservatory of Music" 1988 the first period, page 91.

[3] Ren Rong: "Le Baker art songs", Le Yun Publishing House 1999Edition, the first 151 pages.

[4] However, Xia, Li Wei: "On the United States and the sound of the nation, the three popular singing methods and the difference between", contained "science and technology information" 2008 the tenth period, the first 157 pages.

[5] Ren Rong: "Singing and Art Singing," Le Yun Press, 2008, p. 232. 